\title{
The need to scale up HIV indicator condition-guided testing for early case-finding: a case-control study in primary care
}

Ivo K. Joore ${ }^{*}$, Denise E. Twisk², Ann M. Vanrolleghem³ ${ }^{3}$ Maria de Ridder ${ }^{3}$, Suzanne E. Geerlings ${ }^{4}$, Jan E. A. M. van Bergen ${ }^{1,5}$ and Ingrid V. van den Broek ${ }^{2}$

\begin{abstract}
Background: European guidelines recommend offering an HIV test to individuals who display HIV indicator conditions (ICs). We aimed to investigate the incidence of ICs in primary care reported in medical records prior to HIV diagnosis.

Methods: We did a cross-sectional search in an electronic general practice database using a matched case-control design to identify which predefined ICs registered by Dutch GPs were most associated with an HIV-positive status prior to the time of diagnosis.

Results: We included 224 HIV cases diagnosed from 2009 to 2013, which were matched with 2,193 controls. Almost two thirds ( $n=136,60.7 \%$ ) of cases were diagnosed with one or more ICs in the period up to five years prior to the index date compared to $18.7 \%(n=411)$ of controls. Cases were more likely to have an IC than controls: in the one year prior to the index date, the odds ratio (OR) for at least one condition was 11.7 (95\% Cl: 8.3 to 16.4). No significant differences were seen in the strength of the association between HIV diagnosis and ICs when comparing genders, age groups or urbanisation levels. There is no indication that subgroups require a different testing strategy.
\end{abstract}

Conclusions: Our study shows that there are opportunities for IC-guided testing in primary care. We recommend that IC-guided testing be more integrated in GPs' future guidelines and that education strategies be used to facilitate its implementation in daily practice.

Keywords: Case-control studies, General practice, HIV infections/prevention \& control, HIV infections/epidemiology, Primary healthcare

\section{Background}

In 2014, UNAIDS set the challenging goal to end the AIDS epidemic by 2030 [1]. UNAIDS stated that worldwide in 2020, $90 \%$ of all people living with HIV should be aware of their HIV status, $90 \%$ of all diagnosed HIV infected people should receive antiretroviral therapy, and of that group $90 \%$ should achieve viral suppression [1].

\footnotetext{
* Correspondence: i.k.joore@amc.uva.nl

${ }^{1}$ Department of General Practice, Division Clinical Methods and Public Health, Academic Medical Center, Meibergdreef 9, 1100, DE, Amsterdam, The Netherlands

Full list of author information is available at the end of the article
}

By the end of 2014, 19,382 persons in the Netherlands, or $88 \%$ of the estimated total number of persons living with HIV, had been diagnosed with the infection. In total, 16,821 had started treatment, and of these 15,463 had achieved viral suppression [2]. Our country is thus close to achieving the UNAIDS '90-90-90' target of 73\% of all people with HIV virally suppressed [1]. However, in recent years there are still approximately 1000 newly diagnosed HIV infections in the Netherlands each year [2]. In 2014, 44\% of newly diagnosed persons presented late for care $\left(\mathrm{CD} 4\right.$ count $<350$ cells $/ \mathrm{mm}^{3}$ or with an AIDS-defining event regardless of CD4 count) [2]. 
The insight of starting treatment as prevention, demonstrated public health benefit of early treatment [3]. Recently, data appeared that proved that initiating antiretroviral therapy after HIV diagnosis regardless of CD4 count improved the health prospects of the person being treated $[4,5]$. These findings reinforce the need to detect HIV as early as possible and the importance of linkage to care.

People who are unaware of their infection play an important role in maintaining the HIV epidemic [6]. Dutch general practitioners (GPs) act as gatekeeper to clinical care and are an important point of referral into specialised HIV care [7]. Every Dutch person is required to register with a GP and 75\% contacts their GP at least once per year [8]. About two thirds of sexually transmitted infection (STI) care is provided by GPs and one third by STI clinics $[7,9]$. The costs of STI tests and medication at the GP are covered by mandatory health insurance, only after the out-of-pocket maximum has been reached [10]. One third of all HIV infections in the Netherlands are diagnosed by GPs [2]. A Dutch study also showed that GPs reach groups of persons at risk of HIV that are not reached by STI clinics, which underlines the important role of primary care in fighting the HIV epidemic $[2,11]$. In several European countries, primary care is a setting for creating opportunities to detect HIV as early as possible [11-14].

Dutch GP guidelines already promote providerinitiated HIV testing among high-risk populations, but this strategy alone shows limits in the implementation to detect HIV-infected people [11]. For example, GPs may find it difficult to have complex conversations about sexual risk behaviour $[15,16]$. The deployment of the HIV indicator condition (IC)-guided testing strategy in primary care is a new development that was included in an update of Dutch STI guidelines for GPs that appeared at the end of 2013 [17]. ICs are defined as conditions that are associated with a prevalence of undiagnosed HIV in excess of $0.1 \%$ and AIDS-defining conditions $[18,19]$.

A UK case-control study in primary care found multiple ICs that were associated with a subsequent HIV diagnosis [20].

A Dutch case-control pilot study conducted in a higher HIV-prevalence area showed that one or more ICs were observed prior to diagnosis among cases compared to controls [21]. The results of this study cannot be extrapolated to the Dutch national level, as it was performed in six general practices that were located in a higher HIV-prevalence area.

The aim of the present study was to investigate the incidence of ICs reported in medical records up to five years prior to HIV diagnosis among HIV cases compared to matched controls using a primary care database representative of the general population.

\section{Methods}

We carried out a retrospective population-based nested case-control study; data were retrieved from electronic patient medical records (EMRs).

\section{Data source}

The Integrated Primary Care Information (IPCI) database is a longitudinal primary care research database managed at the Erasmus University Medical Center in Rotterdam, the Netherlands [22, 23]. This database contains the EMRs of 747 Dutch GPs [23]. The EMRs contain demographic information (gender, date of birth and living area) and medical information routinely collected during consultations, including laboratory results, medical diagnoses, prescriptions and treatments. The standard information recorded in EMRs does not include sexual orientation or ethnicity. All patient information in the IPCI database is anonymous. The database incorporates a considerable proportion (about 10\%) of the total Dutch population, making it representative of the general population, with some underrepresentation of elderly people living in nursing homes [24]. The Supervisory Board of the IPCI database approved the use of IPCI data for our study. Approval by an ethics committee was not necessary for this retrospective study because only anonymous data were used. The researchers had no access to the identity the patients or the GPs.

\section{Study population}

The study population from which cases and controls were extracted consisted of all persons in the database who were 18 years or older and registered at one of the GP practices during the period from 1 January 2009 up to 31 December 2013 (total of five years).

Cases were defined as HIV-positive individuals. If no HIV diagnosis was recorded, an individual could act as control.

Potential cases were selected by extracting the International Classification of Primary Care (ICPC) B90 code 'HIV infection' from the EMRs [25]. In addition, EMRs that contain the words 'HIV' and 'AIDS' in the open text evaluation fields were extracted. EMRs with a B25 code ('fear of HIV/AIDS') but without a B90 code were excluded, because these were people who had visited their GP for an HIV test but were not diagnosed with HIV.

Potential cases were manually validated. The extraction of potential cases was performed in duplicate by two of the project's researchers (IKJ and DT). Discrepancies were discussed until consensus was reached. Uncertain potential cases were presented to a third researcher (IvdB). Cases were matched to controls (up to a maximum of 10) for age, gender and registration at the same general practice in the same calendar year and at 
least one year of registration time (follow-up time) prior to the index date (date of HIV diagnosis in cases and matched date in the control group). Controls were selected from persons without an ICPC B90 code in their EMRs. Cases could be selected as controls until the year before they became a case. The number of selected controls per case depended on the availability. Selecting as many controls as possible per case ensures maximum statistical power in matched case-control studies to detect differences in the occurrence of rare events [26].

For the confirmed cases within the study period (2009-13) and their matched controls, a history of five years of patient EMRs of validated registration time before the index date was included if available, but at least one year was required (i.e. practices are included in the IPCI database after data collection checks; information or EMRs prior to validation are only included as 'patient history', and are not counted as validated registration time). The inclusion of the cases was limited by the start date of the GP participation in IPCI or by the date the patient registered with the GP prior to the index date (date of HIV diagnosis).

\section{HIV indicator conditions}

A total of 26 predefined ICs were selected from the list of ICs with an associated (undiagnosed) HIV prevalence of $>0.1 \%$ (see Table 1) $[18,21]$. The selection criteria for inclusion ICs were described in an earlier pilot study and included only conditions that Dutch GPs may diagnose themselves (as opposed to the ones diagnosed by medical specialists/in secondary care) [21]. Conditions that are unlikely to be diagnosed by a GP were excluded. Where necessary, specific case definitions ('operational definitions') were developed for manual searching in the EMRs of the IPCI database. Also, for each IC ICPC code, common medical terminology, abbreviations and synonyms used by the GP or the patient were marked in the EMRs.

A distinction was made between the search for specific diagnoses and that for more general/common symptoms. ICs defined as diagnoses were searched for in the complete text of the EMR, while the symptoms were only searched for in the open text evaluation fields of the EMRs, where most of the important symptoms are reported.

A mononucleosis-like illness was considered if at least two of the following symptoms were present in the EMR's open evaluation text fields: fever, swollen lymph glands and rash with or without pharyngitis, muscle aches and feeling sick. If there were symptoms in the evaluation text fields that might indicate a mononucleosis-like illness, we also searched the other text fields for validating evidence.

The duration of the search period was one to five years prior to the index date, depending on the availability in
Table 1 Operational definitions of HIV indicator conditions

\begin{tabular}{|c|c|}
\hline HIV indicator conditions [18] & $\begin{array}{l}\text { Operational definition of predefined HIV } \\
\text { indicator conditions used for search in } \\
\text { the EMRs* }\end{array}$ \\
\hline $\begin{array}{l}\text { Sexually transmitted } \\
\text { infections }\end{array}$ & $\begin{array}{l}\text { Chlamydia, gonorrhoea, syphilis, hepatitis } \\
\text { B, genital herpes, lymphogranuloma } \\
\text { venereum, condyloma acuminata and } \\
\text { trichomoniasis }\end{array}$ \\
\hline Chlamydia & Chlamydia \\
\hline Gonorrhoea & Gonorrhoea \\
\hline Syphilis & Syphilis \\
\hline $\begin{array}{l}\text { Acute or chronic } \\
\text { Hepatitis B }\end{array}$ & Hepatitis B \\
\hline Genital Herpes & Genital herpes \\
\hline $\begin{array}{l}\text { Lymphogranuloma } \\
\text { venereum }\end{array}$ & Lymphogranuloma venereum \\
\hline Condyloma acuminata & Condyloma acuminata \\
\hline Trichomoniasis & Trichomoniasis \\
\hline Hepatitis A & Hepatitis A \\
\hline Acute or chronic Hepatitis C & Hepatitis C \\
\hline Herpes zoster & Herpes zoster \\
\hline Severe or atypical psoriasis & Psoriasis \\
\hline $\begin{array}{l}\text { Seborrheic dermatitis/ } \\
\text { exanthema }\end{array}$ & Seborrhoeic dermatitis \\
\hline Cervical dysplasia & Cervical dysplasia \\
\hline $\begin{array}{l}\text { Community-acquired } \\
\text { pneumonia }\end{array}$ & Pneumonia \\
\hline Unexplained oral candidiasis & Oral candidiasis \\
\hline Mononeuritis & Mononeuritis \\
\hline Peripheral neuropathy & Peripheral neuropathy \\
\hline Mononucleosis-like illness & $\begin{array}{l}\text { Mononucleosis-like illness is defined as } \\
\text { illness with at least two of these } \\
\text { symptoms: rash, fever and swollen lymph } \\
\text { glands, with or without muscle aches, } \\
\text { sore throat and feeling sick. }\end{array}$ \\
\hline Unexplained fever & Fever \\
\hline Unexplained weight loss & Weight loss \\
\hline $\begin{array}{l}\text { Unexplained } \\
\text { lymphadenopathy }\end{array}$ & Lymphadenopathy \\
\hline $\begin{array}{l}\text { Unexplained chronic } \\
\text { diarrhoea }\end{array}$ & Diarrhoea \\
\hline $\begin{array}{l}\text { Unexplained leukocytopenia } \\
\text { lasting }>4 \text { weeks }\end{array}$ & Leukocytopenia \\
\hline $\begin{array}{l}\text { Unexplained } \\
\text { thrombocytopenia } \\
\text { lasting }>4 \text { weeks }\end{array}$ & Thrombocytopenia \\
\hline $\begin{array}{l}\text { Unexplained chronic renal } \\
\text { impairment }\end{array}$ & Chronic renal impairment \\
\hline
\end{tabular}

*EMR Electronic medical record

the EMR. The history time of a control was matched to the history time of its cases, so that cases did not have a history time different from that of their matched controls. 
The incidence of newly diagnosed ICs in the five years prior to index date was classified as 1) yes recorded (at least once); 2) absent; and 3) uncertain. Incident ICs and their date of diagnosis were manually transferred into a validation tool. If a person had multiple consultations for the same IC, we used the most recent one before the index date that was recorded by the GP. The search for incidence ICs was carried out in duplicate by the same two researchers (IKJ, DT). They were not blinded for HIV diagnosis in the EMRs as this was not possible due to technical limitations. A third researcher ( $\operatorname{lvdB})$ was consulted if consensus could not be reached or if ICs were classified as uncertain.

\section{HIV testing in persons diagnosed with STIs}

According to the Dutch GP guidelines, persons who are diagnosed with chlamydia, gonorrhoea, syphilis or hepatitis B should be advised to have an HIV test. [17] We did a search in the EMRs in the case-control dataset to find out whether patients diagnosed with STIs had been tested for HIV in the same or follow-up consultation(s) within a time window of three months.

\section{Statistical analyses}

We performed conditional logistic regression to investigate whether having at least one STI or IC prior to the index date was associated with testing HIV positive. We performed exact conditional logistic regression to investigate whether specific ICs prior to the index date were associated with testing HIV positive. For very small or zero incidence rates among the cases or controls, odds ratios (ORs) were estimated with 'median unbiased estimate'. Sensitivity analyses were performed, comparing the associations between ICs and HIV diagnosis when including versus not including unconfirmed (classified as 'uncertain') ICs. Furthermore, the interaction of presence of any IC with gender, age group and urbanisation level was tested in a conditional logistic regression model.

Confidence intervals for the percentages of HIV testing in STI diagnosed patients were obtained by Wilson score method [27].

Analyses were performed with SPSS (version 19.0, IBM, USA) except for the exact logistic regression, for which STATA (version 13.1, College Station, TX) was used.

\section{Results}

\section{Patient characteristics of cases and controls}

The eligible study population (18 years and older) consisted of the EMRs of $1,255,440$ persons (Fig. 1). The search algorithm identified 2,068 patients as potential HIV-positive cases. First, patients with a B25 code ('fear of HIV/AIDS') but without a B90 code ('HIV infection') were excluded $(n=452)$. Of the remaining 1,616 potential cases, 897 patients were excluded because no HIV

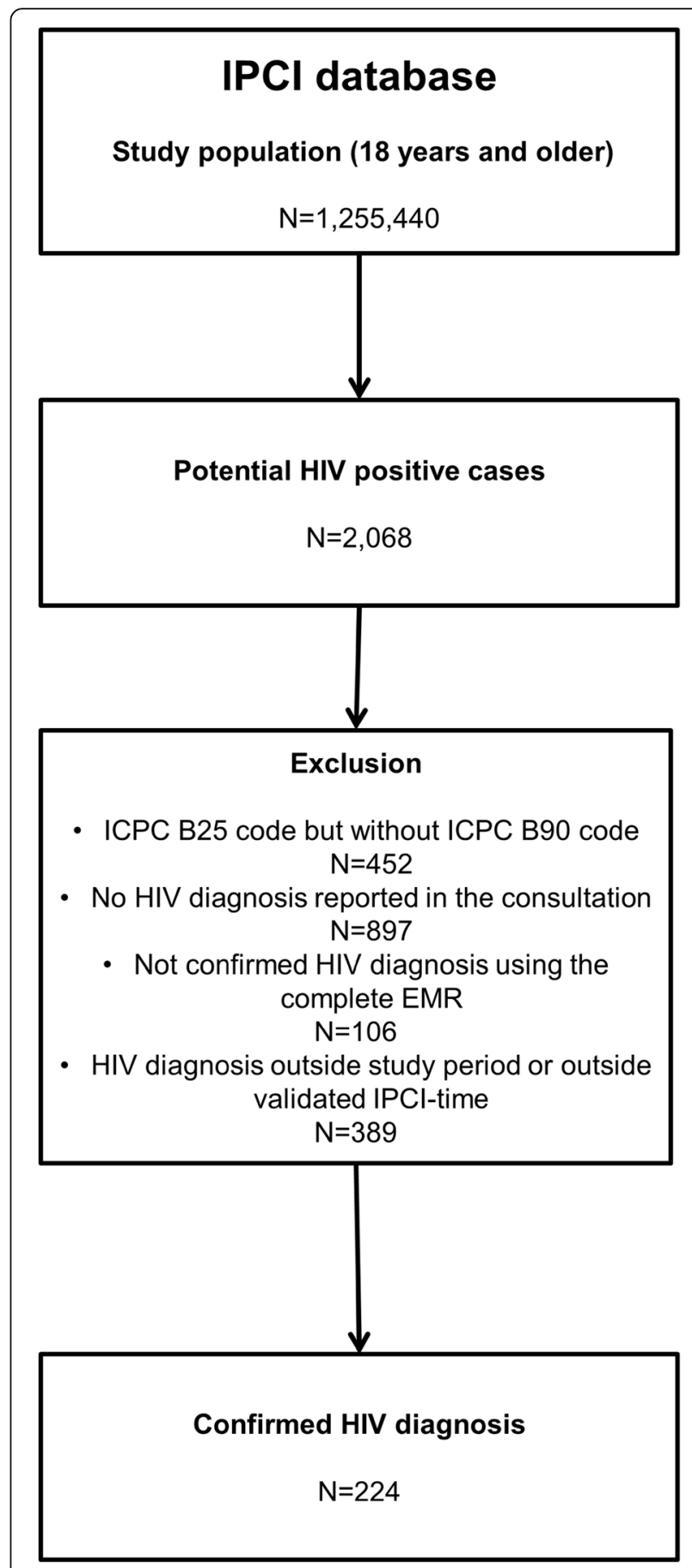

Fig. 1 Number of confirmed HIV diagnosis in the IPCI database 2009-2013

diagnosis was reported in the consultation. For the 719 potential cases a more in-depth evaluation was conducted using the complete EMR to confirm HIV diagnosis; the diagnosis was confirmed in 613 cases. Patients with an HIV diagnosis outside the study period $(n=319)$ or outside the validated IPCI time $(n=70)$ were excluded. 
In total, 224 cases from 135 general practices were matched with 2,193 controls (HIV-negative individuals). The majority $(88.4 \%)$ of cases were male, the median age was 40 (IQR 31 to 47 ) and 55.8\% lived in areas with a high level of urbanisation (Table 2).

\section{HIV indicator conditions}

Almost two thirds $(n=136,60.7 \%)$ of cases had been diagnosed with one or more ICs up to five years prior to the index date, compared to $18.7 \%(n=411)$ of controls (Table 3).

Cases had a higher probability of having IC than controls: in the one year prior to the index date, the OR for at least one condition compared to no condition was 11.7 (95\% CI: 8.3 to 16.4 ) (Table 3).

Recorded STI episodes in the one year prior to the index date were also associated with the occurrence of HIV: for at least one STI compared to no STI the OR was 32.2 (95\% CI: 17.7 to 58.5 ). The proportions of the number of

Table 2 Patient characteristic of cases and matched controls

\begin{tabular}{|c|c|c|c|c|}
\hline & \multicolumn{2}{|c|}{ Cases } & \multicolumn{2}{|c|}{ Controls } \\
\hline & $\bar{N}$ & $\%$ & $\bar{N}$ & $\%$ \\
\hline Total study population & 224 & & 2,193 & \\
\hline \multicolumn{5}{|l|}{ History prior to index date } \\
\hline Between 1 and 2 years & 30 & 13.4 & 289 & 13.2 \\
\hline Between 2 and 3 years & 27 & 12.1 & 270 & 12.3 \\
\hline Between 3 and 4 years & 7 & 3.1 & 70 & 3.2 \\
\hline Between 4 and 5 years & 15 & 6.7 & 150 & 6.8 \\
\hline More than 5 years & 145 & 64.7 & 1,414 & 64.5 \\
\hline \multicolumn{5}{|l|}{ Gender } \\
\hline Male & 198 & 88.4 & 1,933 & 88.1 \\
\hline Female & 26 & 11.6 & 260 & 11.9 \\
\hline \multicolumn{5}{|l|}{ Age at index date } \\
\hline 18 to 39 years & 80 & 35.7 & 788 & 35.9 \\
\hline 40 to 49 years & 97 & 43.3 & 946 & 43.1 \\
\hline 50 to 59 years & 32 & 14.3 & 309 & 14.1 \\
\hline 60 years and older & 15 & 6.7 & 150 & 6.8 \\
\hline \multicolumn{5}{|l|}{ Urbanisation level } \\
\hline very high (>2,500 addresses per km2) & 76 & 33.9 & 633 & 28.9 \\
\hline high (1,500 - 2,500 addresses per km2) & 49 & 21.9 & 522 & 23.8 \\
\hline medium (1,000 - 1,500 addresses per km2) & 21 & 9.4 & 252 & 11.5 \\
\hline low (500 - 1,000 addresses per km2) & 9 & 4.0 & 113 & 5.2 \\
\hline not urban/rural ( $<500$ addresses per km2) & 4 & 1.8 & 61 & 2.8 \\
\hline Missing & 65 & 29.0 & 612 & 27.9 \\
\hline \multicolumn{5}{|l|}{ Socially deprived area (on 4-digit postal code area) } \\
\hline Yes & 26 & 11.6 & 226 & 10.3 \\
\hline No & 198 & 88.4 & 1,967 & 89.7 \\
\hline
\end{tabular}

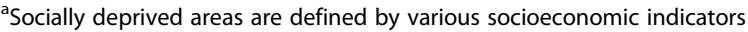
determined per 4-digit postal code
Table 3 The proportion of persons diagnosed with one or more STI or HIV indicator condition among HIV cases compared to matched controls

\begin{tabular}{|c|c|c|c|c|c|c|}
\hline \multicolumn{2}{|c|}{$\begin{array}{l}\text { Cases } \\
(N=224)\end{array}$} & \multicolumn{2}{|c|}{$\begin{array}{l}\text { Controls } \\
(N=2,193)\end{array}$} & \multirow[b]{2}{*}{ OR } & \multirow[b]{2}{*}{$95 \% \mathrm{Cl}$} & \multirow[b]{2}{*}{$P$ value } \\
\hline $\mathrm{N}$ & $\%$ & $\mathrm{~N}$ & $\%$ & & & \\
\hline
\end{tabular}

Number of STIs per person in one year prior to index date

$\begin{array}{lllll}\text { None } & 174 & 78.1 & 2,169 & 98.9\end{array}$

At least one $\begin{array}{lllllll}50 & 21.9 & 24 & 1.1 & 32.2 & 17.7 \text { to } 58.5<\mathbf{0 . 0 0 0 1}\end{array}$

Number of ST/s per person up to five years prior to index date

$\begin{array}{lllll}\text { None } & 142 & 63.4 & 2,125 & 96.9\end{array}$

At least one $\begin{array}{lllllll}82 & 36.6 & 68 & 3.1 & 25.3 & 16.1 \text { to } 39.9<0.0001\end{array}$

Number of HIV indicator conditions per person one year prior to index date $\begin{array}{lllll}\text { None } & 125 & 55.8 & 2,032 & 92.7\end{array}$

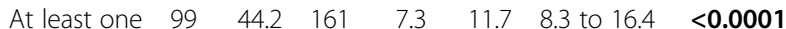

Number of HIV indicator conditions per person up to five years prior to index date

\begin{tabular}{lllllllll} 
None & 88 & 39.3 & 1,782 & 81.3 & & & \\
At least one & 136 & 60.7 & 441 & 18.7 & 8.1 & 5.9 to 11.1 & $<\mathbf{0 . 0 0 0 1}$ \\
\hline
\end{tabular}

Statistical significance indicated in bold

STIs and ICs per person prior to index date are reported in Additional file 1.

The ICs most strongly associated with the occurrence of HIV were gonorrhoea (OR $=77.1,95 \% \mathrm{CI}: 27.3$ to $300.3)$ and syphilis (OR $=52.0,95 \%$ CI: 17.6 to 208.2) (Table 4). Several ICs were not observed in either the cases or the control group, i.e. chronic renal impairment, hepatitis A and leukocytopenia.

When uncertain diagnoses were included in the reported ICs, lymphogranuloma venereum $(\mathrm{OR}=20.0$; 95\% CI: 1.0 to 1179.9 ) was also associated with the occurrence of HIV diagnosis.

The OR for the occurrence of ICs was higher for men than for women, but the difference was not significant (see Table 5). Age group or urbanisation level also had no significant effect on the strength of the association between HIV diagnosis and ICs.

\section{HIV testing in persons diagnosed with STIs}

In $32.1 \%$ (95\% CI: 17.9 to 50.7) of persons diagnosed with syphilis ( $9 / 28$ of the cases and controls) no HIV test was reported in the EMRs in the same or follow-up consultation(s) within a time window of three months; for gonorrhoea this was $44.7 \%$ (95\% CI: 30.1 to 60.3 ), (17/38), for hepatitis B 61.5\% (95\% CI: 35.5 to 82.3), (8/13) and for chlamydia 54.2\% (95\% CI: 40.3 to 67.4$)$, (26/48).

\section{Discussion}

Since 2012, European guidelines recommend IC-guided testing in primary care. This new strategy is also mentioned in the updated Dutch national STI guideline for 
Table 4 The incidence of clinical- and symptoms-related HIV indicator conditions among HIV cases compared to matched controls

\begin{tabular}{|c|c|c|c|c|c|c|c|}
\hline & \multicolumn{2}{|c|}{ Cases $(N=224)$} & \multicolumn{2}{|c|}{ Controls $(N=2,193)$} & \multirow[b]{2}{*}{$\mathrm{OR}$} & \multirow[b]{2}{*}{$95 \% \mathrm{Cl}$} & \multirow[b]{2}{*}{$P$ value } \\
\hline & $\bar{N}$ & $\%$ & $\bar{N}$ & $\%$ & & & \\
\hline \multicolumn{8}{|l|}{ Clinical diagnosis } \\
\hline Gonorrhoea & 33 & 14.7 & 5 & 0.2 & 77.1 & 27.3 to 300.3 & $<0.0001$ \\
\hline Syphilis & 22 & 9.8 & 6 & 0.3 & 52.0 & 17.6 to 208.2 & $<0.0001$ \\
\hline Leukocytopenia* & 2 & 0.9 & 0 & & 24.1 & 1.9 to $\infty^{*}$ & 0.02 \\
\hline Trichomoniasis & 2 & 0.9 & 1 & 0 & 20.0 & 1.0 to $1,179.9$ & 0.05 \\
\hline Hepatitis B & 9 & 4.0 & 4 & 0.2 & 22.5 & 6.3 to 100.0 & $<0.0001$ \\
\hline Hepatitis C & 3 & 1.3 & 2 & 0.1 & 15.0 & 1.7 to 179.6 & 0.01 \\
\hline Thrombocytopenia & 4 & 1.8 & 4 & 0.2 & 12.0 & 2.0 to 83.1 & $<0.01$ \\
\hline Lymphogranuloma venereum & 1 & 0.4 & 1 & 0 & 10.0 & 0.1 to 785.0 & 0.35 \\
\hline Mononeuritis & 1 & 0.4 & 1 & 0 & 10.0 & 0.1 to 785.0 & 0.35 \\
\hline Cervical dysplasia & 6 & 2.7 & 11 & 0.5 & 8.1 & 2.0 to 34.6 & $<0.01$ \\
\hline Chlamydia & 20 & 8.9 & 28 & 1.3 & 8.5 & 4.2 to 17.0 & $<0.0001$ \\
\hline Genital herpes & 8 & 3.6 & 7 & 0.3 & 10.2 & 3.1 to 33.7 & 0.0001 \\
\hline Condyloma acuminata & 19 & 8.5 & 25 & 1.1 & 7.9 & 4.0 to 15.1 & $<0.0001$ \\
\hline Oral candidiasis & 3 & 1.3 & 7 & 0.3 & 4.5 & 0.7 to 21.3 & 0.11 \\
\hline Mononucleosis-like illness & 3 & 1.3 & 6 & 0.3 & 4.9 & 0.8 to 23.1 & 0.09 \\
\hline Pneumonia & 25 & 11.2 & 79 & 3.6 & 3.6 & 2.1 to 5.9 & $<0.0001$ \\
\hline Herpes zoster & 10 & 4.5 & 32 & 1.5 & 3.2 & 1.4 to 6.9 & $<0.01$ \\
\hline Chronic renal impairment* & 0 & 0 & 3 & 0.1 & 2.6 & 0 to 24.2 & 1.00 \\
\hline Hepatitis $A^{*}$ & 0 & 0 & 4 & 0.2 & 1.9 & 0 to 15.1 & 1.00 \\
\hline Psoriasis & 6 & 2.7 & 34 & 1.6 & 1.8 & 0.6 to 4.5 & 0.30 \\
\hline Seborrhoeic dermatitis & 7 & 3.1 & 60 & 2.7 & 1.2 & 0.4 to 2.8 & 0.83 \\
\hline \multicolumn{8}{|l|}{ Symptoms } \\
\hline Weight loss & 7 & 3.1 & 19 & 0.9 & 3.9 & 1.3 to 10.1 & 0.01 \\
\hline Lymphadenopathy & 9 & 4.0 & 31 & 1.4 & 3.2 & 1.3 to 7.3 & 0.01 \\
\hline Fever & 8 & 3.6 & 29 & 1.3 & 2.8 & 1.1 to 6.3 & 0.03 \\
\hline Diarrhoea & 18 & 8.0 & 79 & 3.6 & 2.5 & 1.4 to 4.4 & $<0.01$ \\
\hline Peripheral neuropathy & 5 & 2.2 & 25 & 1.1 & 0.7 & 0.1 to 2.8 & 0.95 \\
\hline
\end{tabular}

OR estimated with 'Median Unbiased Estimate' displayed with an asterisk $\left(^{*}\right) . \infty=$ infinity

Statistical significance indicated in bold

GPs which was published at the end of 2013. Our findings strengthen the evidence for implementation of this new strategy as we showed that ICs were more commonly diagnosed in HIV-positive persons than in matched controls, in a period up to five years prior to HIV diagnosis. HIV testing after detection of other STIs has already been recommended for years. However, our results showed that an HIV test is not always performed according to the medical files. Our data showed no indication that the ICguided testing strategy would have a different effect in sex- or age-based subgroups or in high-prevalence areas.

\section{Discussion of findings}

A Spanish cross-sectional study showed that offering HIV testing to patients diagnosed with an IC could be cost-effective in primary care since the prevalence of HIV in these patients was higher than $0.1 \%$ for most of the suggested ICs [28]. Also, this Spanish study showed that ICs were frequently diagnosed by the GP, however, HIV testing occurred in only $18.6 \%$ of the patients with ICs. A Dutch case-control pilot study showed that more than half of all cases (58.5\%) in a high-prevalence area had one or more ICs in the five years prior to HIV diagnosis [21]. A UK general practice case-control study found that $25.8 \%$ of HIV cases had presented with an ICs one year prior to the HIV diagnosis date [20]. In our study, $44.2 \%$ of cases had one or more ICs one year prior to the HIV diagnosis date. Also, a high number of cases were from highly urbanised areas, which are known to have a higher percentage of migrants [29]. The large 
Table 5 Association of HIV diagnosis and HIV indicator conditions by gender, age group or urbanisation level

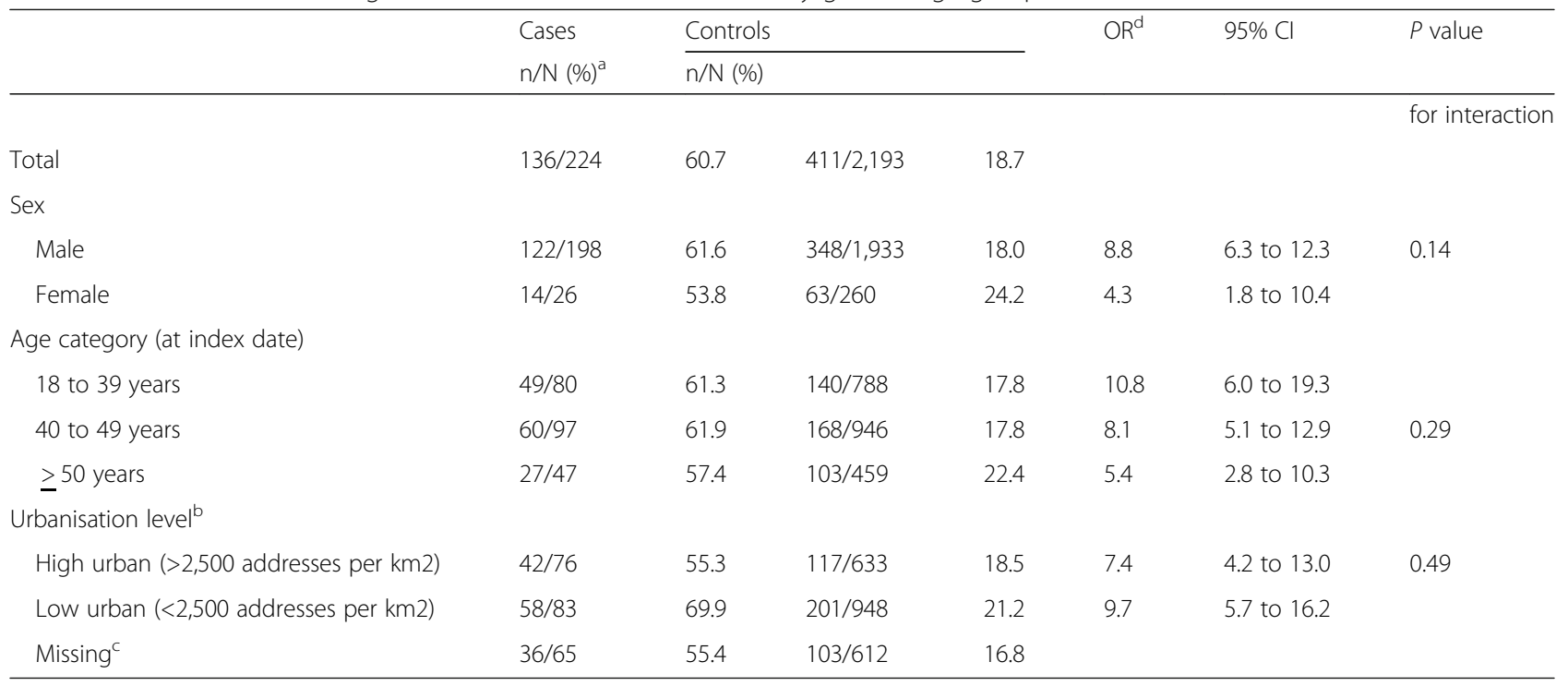

${ }^{a} n=$ number of cases or controls with HIV indicator conditions, $N=$ total number of cases or controls, \%= percentage with HIV indicator condition

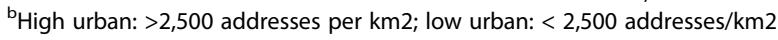

'Subjects with missing urbanisation level were not included in the analysis

${ }^{d}$ additional effect of gender/age/urbanisation level on the likelihood for an HIV-diagnosis after presence of HIV indicator conditions

numbers of local residents who originate from countries where HIV is endemic, and who are known to present to care late, may well account for the higher percentage of ICs $[2,21]$. This provider-initiated strategy could be helpful in finding newly diagnosed HIV patients as early as possible.

In a qualitative study, Dutch GPs suggested that implementing the IC-guided testing might be more beneficial in a higher HIV-prevalence area than in areas with a lower HIV-prevalence [30]. In our study, no significant differences were seen in the strength of the association between HIV diagnosis and ICs when comparing genders, age groups or urbanisation levels. Our study suggests that IC-guided testing is not restricted to highprevalence areas or subgroups.

Dutch national GP guidelines recommend that persons in high-risk groups should be tested for all five major STIs, namely chlamydia, gonorrhoea, hepatitis B, syphilis and HIV [17]. In our study, $36.6 \%$ of the cases had one or more STI(s) up to five years prior to diagnosis compared to $3.0 \%$ of the controls. The European guidelines recommend HIV testing for all STIs with an undiagnosed HIV prevalence of $>0.1 \%$ [18]. This implies that all patients in the general population with an unspecified STI diagnosis should be tested for HIV. In the Netherlands, persons who are diagnosed with an STI in primary care should be evaluated in terms of patient's risk-assessment and symptoms to determine whether they should be further tested for STIs [11, 17]. Chlamydia is highly prevalent among Dutch patients who are in groups that are presumed to have a low risk of HIV.
There is still debate about the need to test for HIV in primary care if chlamydia is found in a person not classified as being in a high-risk group [9]. Also, in our study the ORs for gonorrhoea and syphilis were higher than for chlamydia.

Acute HIV infection is a syndrome that can present as a mononucleosis-like illness, and therefore its detection can lead to the detection of HIV as early as possible. Mononucleosis-like illness includes such symptoms as fever, malaise, skin rash and generalised lymphadenopathy [31, 32]. Mononucleosis-like illness was reported in $1.3 \%$ of HIV cases in the five years prior to diagnosis compared to $0.3 \%$ of the controls. The low percentage found in the case group could be explained by the fact that a mononucleosis-like illness is not always documented in the EMRs. Also, GPs are not always aware of this acute syndrome [31, 32]. To increase the detection of acute HIV infection, GPs could be better informed about mononucleosis-like illness and the possible relationship with acute HIV infection.

\section{Strengths and limitations}

This study was carried out in a GP network covering a representative sample of the Dutch population. Cases and ICs were searched for in the EMRs with the help of open source information extraction algorithms, which are known to significantly improve case detection when combined with codes [33].

The controls were matched with the cases to limit confounding. The selection of 10 controls per case 
ensured more statistical power to detect differences in rare events of ICs [26].

Reporting bias was minimised because the EMRs were based on observations that were routinely recorded before the HIV diagnosis was made. Therefore, there is no reason for differences between cases and controls in the accuracy of the information collected.

During data extraction we searched for ICs defined as 'symptoms' (e.g. fever) in the evaluation line of the consultation form (considered to be the final conclusion of the GP), to avoid the risk of overestimating this IC (e.g. fever often mentioned as complaint). As a result, an underestimation is likely and associations between symptoms and HIV diagnosis may be even stronger.

Not all ICs are likely to have been recorded in the EMRs [34]. STIs may have been diagnosed elsewhere. In the Netherlands, STI care is provided by GPs and STI clinics [7, 17]. Results from STI clinics are not always sent to the GP, which could cause an underestimation of the number of ICs [11]. For the same reason, the proportion not tested for HIV after an STI diagnosis may have been overestimated, since HIV tests may be performed at STI clinics. For example, we found that for $32 \%$ of persons diagnosed with syphilis, no HIV test was reported in the same or follow-up consultation(s).

If a person had multiple consultations for an IC, we used only the most recent one before the index date that was recorded by the GP. A limitation is that the information of repeated episodes was disregarded; a patient could have been diagnosed multiple times with the same IC prior to diagnosis, for example, multiple chlamydia diagnoses. We chose for this method because it was difficult to determine from the records whether a condition was diagnosed twice or if the same condition reappeared. This may have led to a slight underestimation of the associations between IC conditions and HIV diagnosis; however, we still found quite strong and significant associations.

Potential confounders or effect modifiers, such as ethnicity, sexual preference and socioeconomic status, could not be included in the analyses, because the standard information recorded in patients' medical files does not include these characteristics [21]. In other European countries, too, sexual risk behaviour and sexual orientation are not included in EMRs in primary care $[15,16]$. However, the strength of ICguided testing is that it does not depend on patient characteristics: HIV tests are not offered specificly to groups labelled as being at risk and thereby avoids potentially complex conversations about sexual risk behaviour and/or ethnicity $[15,16,35]$. Therefore, ICs could help GPs to bypass some of the barriers presented by these conversations and thus help to normalise the use of the HIV test. [30]

\section{Conclusion}

Our study showed that there are opportunities for IC-guided testing in primary care in the Netherlands. Unlike risk-based testing, this provider-initiated strategy is also applicable for all patients.

The majority of the ICs in the European guideline are not often seen by GPs, although all ICs are listed as relevant for HIV testing in primary care [18]. We recommend to determine a specific list of ICs that are more commonly seen in primary care and thus help GPs to implement IC-guided testing.

The context of pre-test information and how the HIV test is offered when an IC is diagnosed is important if patients are to agree to be tested [36, 37]. GPs should be educated about the context of pre-test information and how to offer an HIV test during IC-guided testing, for example, by using an opt-out approach ('You will be tested unless you decline'). Many GPs use educational tools to keep up to date and these are often the first step in an implementation or change process [38]. We recommend that IC-guided testing should be better integrated in GPs' future guidelines and that education strategies be developed to facilitate its implementation in daily practice.

\section{Additional file}

Additional file 1: The proportion of persons classified by number of STIs and HIV indicator conditions in the period of one year or five years prior to the index date among HIV cases compared to matched controls. (DOC $54 \mathrm{~kb}$ )

\section{Abbreviations \\ Cl: Confidence interval; EMR: Electronic patient medical record; GP: General practitioner; IC: HIV indicator condition; ICPC: International Classification of Primary Care; IPCl: Integrated Primary Care Information; OR: Odds ratio; STI: Sexually transmitted infection; UK: United Kingdom; UNAIDS: The Joint United Nations Programme on HIV and AIDS}

\section{Acknowledgements}

Erasmus Department of Medical Information is acknowledged for hosting us and making available their data. All general practitioners who participated in IPCI network from 2009 to 2013 and all participants are gratefully acknowledged.

\section{Funding}

This work was supported by Aids Fonds grant number: 2012074, Amsterdam, the Netherlands.

\section{Availability of data and materials}

Data from IPCI can be accessed to authorized persons at the department of Medical Informatics in line with the privacy and ethical regulations.

\section{Authors' contributions}

DT was involved in the data collection, statistical analyses and first draft of the manuscript. IKJ, AvR and IvdB were involved in the data collection. IKJ, IVdB and MdR performed further statistical analyses. IKJ and IVdB wrote the final manuscript. All authors contributed to the design and/or interpretation, provided feedback and approved the final submitted version of the manuscript. 


\section{Competing interests}

JvB has a part-time position at STI AIDS Netherlands. The mission of this NGO is to control STIs including HIV and to contribute to sexual health. A limited amount of funds is acquired via private sector cooperation, [part of it being farma. This is governed by an explicit code of conduct: http:// www.soaaids.nl/sites/default/files/documenten/Corporate/corporate_ partnership_guidelines.pdf

The other authors declared that they have no competing interests.

\section{Consent for publication}

Not applicable.

\section{Ethics approval and consent to participate}

According to the Medical Research (Human Subjects) Act (WMO), formal approval for this research project by a medical ethics committee was not required. The IPCI system complies with European Union guidelines on the use of data for medical research and has been proven valid for studies. The scientific and ethical advisory board of IPCI network approved this study (number 2014/4). Informed written consent to participate: not applicable.

\section{Author details}

${ }^{1}$ Department of General Practice, Division Clinical Methods and Public Health, Academic Medical Center, Meibergdreef 9, 1100, DE, Amsterdam, The Netherlands. ${ }^{2}$ National Institute for Public Health and the Environment (RIVM), Epidemiology \& Surveillance Unit, Centre for Infectious Disease Control, Bilthoven, The Netherlands. ${ }^{3}$ Department of Medical Informatics, Erasmus University Medical Center, Rotterdam, The Netherlands. ${ }^{4}$ Department of Internal Medicine, Division of Infectious Diseases, Academic Medical Center, Amsterdam, The Netherlands. ${ }^{5}$ STI AIDS Netherlands (SOA AIDS Nederland), Amsterdam, The Netherlands.

Received: 14 April 2016 Accepted: 2 November 2016

\section{Published online: 17 November 2016}

\section{References}

1. 90-90-90 An ambitious treatment target to help end the AIDS epidemic Report, UNAIDS, 2014. http://www.unaids.org/en/resources/documents/ 2014/90-90-90. (Accessed Aug 2016)

2. Van Sighem Al, Gras LA, Smit C, et al. Monitoring Report 2015: Human Immunodeficiency Virus (HIV) Infection in the Netherlands. Stichting HIV Monitoring, Amsterdam: Report; 2015. http://www.hiv-monitoring.nl/ nederlands/onderzoek/monitoring-reports/ (Accessed August 2016).

3. Cohen MS, Chen YQ, McCauley M, Gamble T, Hosseinipour MC, Kumarasamy N, Hakim JG, Kumwenda J, Grinsztejn B, Pilotto JH, et al. Prevention of HIV-1 infection with early antiretroviral therapy. N Engl J Med. 2011;365(6):493-505

4. Lundgren JD, Babiker AG, Gordin F, Emery S, Grund B, Sharma S, Avihingsanon A, Cooper DA, Fatkenheuer G, Llibre JM, et al. Initiation of Antiretroviral therapy in early Asymptomatic HIV Infection. N Engl J Med. 2015;373(9):795-807

5. Danel C, Moh R, Gabillard D, Badje A, Le Carrou J, Ouassa T, Ouattara E, Anzian A, Ntakpe JB, Minga A, et al. A trial of early Antiretrovirals and Isoniazid preventive therapy in Africa. N Engl J Med. 2015;373(9):808-22.

6. van Sighem A, Vidondo B, Glass TR, Bucher HC, Vernazza P, Gebhardt M, de Wolf $F$, Derendinger $S$, Jeannin A, Bezemer $D$, et al. Resurgence of HIV infection among men who have sex with men in Switzerland: mathematical modelling study. PLoS One. 2012;7(9):e44819.

7. Van den Broek IV, Verheij RA, van Dijk CE, et al. Trends in sexually transmitted infections in the Netherlands, combining surveillance data from general practices and sexually transmitted infection centers. BMC Fam Pract. 2010;11:39.

8. Cardol M, van Dijk L, de Jong JD, et al. Second National Study into disease and treatment in family practice. Family practitioner: what does the gatekeeper do? [Tweede nationale studie naar ziekten en verrichtingen in de huisartspraktijk. Huisartsenzorg: wat doet de poortwachter?]. NIVEL/RIVM, 2004. (Kernrapport 2) http://www.nivel.nl/sites/default/files/bestanden/ns2_ rapport2.pdf (Accessed Aug 2016) [In Dutch]

9. van den Broek IVF, van Aar F, van Oeffelen AAM, Woestenberg PJ, Heijne JCM, den Daas C, Hofstraat SHI, Hoenderboom BM, van Wees D, van Sighem Al, Nielen MMJ, van Benthem BHB. Sexually transmitted infections in the Netherlands in 2015. Bilthoven, the Netherlands: National Institute for
Public Health and the Environment (RIVM), 2016. http://www.rivm.nl/ dsresource?objectid=e5493c29-6dc7-4372-969b-9a55d36c88ca\&type= org\&disposition=inline. Accessed Nov 2016 [In Dutch].

10. Government of the Netherlands. Health Insurance. https://www. government.nl/topics/health-insurance. Accessed Nov 2016.

11. Joore IK, Reukers DF, Donker GA, van Sighem Al, Op de Coul EL, Prins JM, Geerlings SE, Barth RE, van Bergen JE, van den Broek IV. Missed opportunities to offer HIV tests to high-risk groups during general practitioners' STI-related consultations: an observational study. BMJ Open. 2016;6(1):e009194.

12. Burns FM, Johnson AM, Nazroo J, Ainsworth J, Anderson J, Fakoya A, Fakoya I, Hughes A, Jungmann E, Sadiq ST, et al. Missed opportunities for earlier HIV diagnosis within primary and secondary healthcare settings in the UK. AIDS. 2008;22(1):115-22.

13. Brawley D, MacConnachie A, Nandwani R, Bell DJ, Fargie F, Fox R, Peters E, Seaton RA, Winter A. Missed opportunities for HIV diagnosis: a three-year audit in the West of Scotland. Scott Med J. 2013:58(3):173-7.

14. Champenois K, Cousien A, Cuzin L, Le Vu S, Deuffic-Burban S, Lanoy E, Lacombe K, Patey O, Bechu P, Calvez M, et al. Missed opportunities for HIV testing in newly-HIV-diagnosed patients, a cross sectional study. BMC Infect Dis. 2013;13:200

15. Vos J, Pype P, Deblonde J, Van den Eynde S, Aelbrecht K, Deveugele M, Avonts D. Collecting and registering sexual health information in the context of HIV risk in the electronic medical record of general practitioners: a qualitative exploration of the preference of general practitioners in urban communities in Flanders (Belgium). Prim Health Care Res Dev. 2015;1-18.

16. Callander D, Bourne C, Pell C, Finlayson R, Forssman B, Baker D, de Wit J, Hocking J, Stoove M, Donovan B, et al. Recording the sexual orientation of male patients attending general practice. Fam Pract. 2015;32(1):35-40.

17. Van Bergen J, Dekker J, Boeke A, Kronenberg E, Van der Spruit R, Burgers J, et al. Dutch College of General Practitioners' guideline STD consultation (first revision) [NHG standaard: Het soa-consult (eerste herziening)]. Huisarts Wet. 2013;56:450-63. https://www.nhg.org/standaarden/volledig/nhgstandaard-het-soa-consult (accessed August 2016).

18. HIV in Europe. HIV Indicator Conditions: Guidance for implementing HIV testing in Adults in Health Care Settings, 2012. http://hiveurope.eu/Portals/ 0/Guidance.pdf.pdf (Accessed Aug 2016)

19. Gokengin D, Geretti AM, Begovac J, Palfreeman A, Stevanovic M, Tarasenko O, Radcliffe K. 2014 European Guideline on HIV testing. Int J STD AIDS. 2014;25(10):695-704

20. Damery S, Nichols L, Holder R, Ryan R, Wilson S, Warmington S, StokesLampard H, Manavi K. Assessing the predictive value of HIV indicator conditions in general practice: a case-control study using the THIN database. Br J Gen Pract. 2013;63(611):e370-377.

21. Joore IK, Arts DL, Kruijer MJ, van Charante EP M, Geerlings SE, Prins JM, van Bergen JE. HIV indicator condition-guided testing to reduce the number of undiagnosed patients and prevent late presentation in a high-prevalence area: a case-control study in primary care. Sex Transm Infect. 2015:91(7):467-72

22. Lamberts $H$, Wood M, Hofmans-Okkes IM. International primary care classifications: the effect of fifteen years of evolution. Fam Pract. 1992;9(3):330-9.

23. van der Lei J, Duisterhout JS, Westerhof HP, van der Does E, Cromme PV, Boon WM, van Bemmel JH. The introduction of computer-based patient records in The Netherlands. Ann Intern Med. 1993;119(10):1036-41.

24. Vlug AE, van der Lei J, Mosseveld BM, van Wijk MA, van der Linden PD, Sturkenboom MC, van Bemmel JH. Postmarketing surveillance based on electronic patient records: the IPCI project. Methods Inf Med. 1999;38(4-5):339-44

25. Soler JK, Okkes I, Wood M, Lamberts $H$. The coming of age of ICPC: celebrating the 21 st birthday of the International Classification of Primary Care. Fam Pract. 2008:25(4):312-7.

26. Hennessy S, Bilker WB, Berlin JA, Strom BL. Factors influencing the optimal control-to-case ratio in matched case-control studies. Am J Epidemiol. 1999;149(2):195-7

27. Wilson EB. Probable inference, the law of succession, and statistical inference. J Am Stat Assoc. 1927;22(158):209-12.

28. Agusti C, Montoliu A, Mascort J, Carrillo R, Almeda J, Elorza JM, Aragon M, Casabona J. Missed opportunities for HIV testing of patients diagnosed with an indicator condition in primary care in Catalonia, Spain. Sex Transm Infect. 2016;92(5):387-92 
29. Non-Western immigrant per town 2010-2040. Improving publich health and health and a clean and safe environment, National Institute for Public Health and the Environment (RIVM), Bilthoven, 2010 [Niet-westerse allochtonen per gemeente 2010-2040. Volksgezondheid Toekomst Verkenning, Nationale Atlas Volksgezondheid, RIVM]: http://www.zorgatlas. nl/beinvloedende-factoren/demografie/etniciteit/niet-westerse-allochtonenper-gemeente-2010-2040/(Accessed Feb 2016)

30. Joore IK, van Roosmalen SL, van Bergen JE, van Dijk N. General practitioners' barriers and facilitators towards new provider-initiated HIV testing strategies: a qualitative study. Int J STD AIDS. 2016, May;20 [Epub ahead of print].

31. Cohen MS, Shaw GM, McMichael AJ, Haynes BF. Acute HIV-1 Infection. N Engl J Med. 2011;364(20):1943-54.

32. Brenner BG, Roger M, Routy JP, Moisi D, Ntemgwa M, Matte C, Baril JG, Thomas R, Rouleau D, Bruneau J, et al. High rates of forward transmission events after acute/early HIV-1 infection. J Infect Dis. 2007:195(7):951-9.

33. Ford E, Carroll JA, Smith HE, Scott D, Cassell JA. Extracting information from the text of electronic medical records to improve case detection: a systematic review. J Am Med Inform Assoc. 2016;23(5):1007-15.

34. Barkhuysen P, de Grauw W, Akkermans R, Donkers J, Schers H, Biermans M. Is the quality of data in an electronic medical record sufficient for assessing the quality of primary care? J Am Med Inform Assoc. 2014;21(4):692-8.

35. Navaza B, Abarca B, Bisoffi F, Pool R, Roura M. Provider-Initiated HIV Testing for Migrants in Spain: a qualitative study with health care workers and foreign-born sexual minorities. PLoS One. 2016;11(2):e0150223.

36. Montoy JC, Dow WH, Kaplan BC. Patient choice in opt-in, active choice, and opt-out HIV screening: randomized clinical trial. BMJ. 2016;532:h6895.

37. Bell SA, Delpech V, Raben D, Casabona J, Tsereteli N, de Wit J. HIV pre-test information, discussion or counselling? A review of guidance relevant to the WHO European Region. Int J STD AIDS. 2016;27(2):97-104.

38. Grol R, Braspenning J, Dijkstra R, Hulscher MMW. Implementatie van NHG-Standaarden: succes of probleem? Huisarts Wet. 2010;53(1):42-6.

\section{Submit your next manuscript to BioMed Central and we will help you at every step:}

- We accept pre-submission inquiries

- Our selector tool helps you to find the most relevant journal

- We provide round the clock customer support

- Convenient online submission

- Thorough peer review

- Inclusion in PubMed and all major indexing services

- Maximum visibility for your research

Submit your manuscript at www.biomedcentral.com/submit

) Biomed Central 